\title{
HYPERBOLE AS A PERSUASION TOOL IN POLITICAL DISCOURSE (THE CASE OF BRITISH POLITICIANS' SPEECH)
}

\author{
Tatyana M. Golubeva \\ Minin State Pedagogical University of Nizhny Novgorod (Minin University), \\ Nizhny Novgorod, Russia
}

\begin{abstract}
The article investigates hyperboles as a persuasion tool in British political discourse. The corpus under analysis comprises scripts of speeches by UK Permanent Representative to the UN Karen Pierce, Prime Minister Theresa May and Foreign Secretary Boris Johnson which are devoted to the incident in Salisbury. The research has shown that to describe the event under study the politicians use rhetoric devices that exaggerate its social and political importance. In political discourse hyperboles have an impact on three modes of persuasion - logos, pathos and ethos, but in political communication the effectiveness of a hyperbole as a persuasion tool mainly depends on ethos, i.e. conditions of a speech act which determine the relevance of this rhetorical device and a speaker's personality. In some statements hyperboles are so efficiently embedded the communicative context that they are interpreted literally. In political discourse persuasion is often implemented through the use of hyperboles and other rhetorical devices (analogy, alliteration, anaphora, climax). The evocative character of hyperbole is key to the implementation of its persuasive function in political discourse. Under the influence of the representations evoked by hyperbole, the object of exaggerated description acquires characteristics which quantitatively and, in some cases, qualitatively differ from its real properties.

Key words: hyperbole, persuasive function, logos, pathos, ethos, metaphorical hyperboles, political discourse, evocation.

Citation. Golubeva T.M. Hyperbole as a Persuasion Tool in Political Discourse (The Case of British Politicians' Speech). Vestnik Volgogradskogo gosudarstvennogo universiteta. Seriya 2. Yazykoznanie [Science Journal of Volgograd State University. Linguistics], 2019, vol. 18, no. 3, pp. 195-205. (in Russian). DOI: https://doi.org/ 10.15688/jvolsu2.2019.3.16
\end{abstract}

УДК $811.111: 82-52$

Дата поступления статьи: 19.06.2019

ББК 81.432.1-51

Дата принятия статьи: 30.09.2019

\section{ПЕРСУАЗИВНОСТЬ ГИПЕРБОЛЫ В ПОЛИТИЧЕСКОМ ДИСКУРСЕ (НА МАТЕРИАЛЕ ВЫСКАЗЫВАНИЙ БРИТАНСКИХ ПОЛИТИКОВ)}

\section{Татьяна Михайловна Голубева}

Нижегородский государственный педагогический университет им. К. Минина (Мининский университет), г. Нижний Новгород, Россия

\footnotetext{
Аннотация. В статье представлен анализ гипербол в британском политическом дискурсе. Материалом для исследования послужили высказывания представителя в ООН К. Пирс, премьер-министра Т. Мэй и министра иностранных дел Б. Джонсона, посвященные теме инцидента в Солсбери. Доказано, что выражения, используемые политиками для характеристики данного события, преувеличивают его общественную и политическую значимость. Выявлено, что в политическом дискурсе гиперболы обусловливают реализацию функции убеждения посредством обращения к логосу, пафосу и этосу. Установлено, что эффективность гиперболы как инструмента убеждения в политике в значительной степени зависит от условий речевой ситуации, детерминирующих уместность употребления данного риторического приема, и личности говорящего. Показано, что искусно встроенные в коммуникативный контекст ги-
} 
перболы могут восприниматься буквально. Наряду с другими риторическими приемами (аналогией, аллитерацией, анафорой, градацией) они усиливают убедительность высказывания. Важную роль в реализации персуазивной функции гиперболы в политическом дискурсе играет способность вызывать определенные представления, в рамках которых объект гиперболической репрезентации приобретает свойства, отличающиеся от его реальных характеристик в количественном, а иногда и качественном отношении.

Ключевые слова: гипербола, персуазивная функция, логос, пафос, этос, метафорические гиперболы, политический дискурс, эвокативность.

Цитирование. Голубева Т. М. Персуазивность гиперболы в политическом дискурсе (на материале высказываний британских политиков) // Вестник Волгоградского государственного университета. Серия 2, Языкознание. -2019. - Т. 18, № 3. - С. 195-205. - DOI: https://doi.org/10.15688/jvolsu2.2019.3.16

\section{Введение}

На протяжении веков гипербола являлась предметом активного изучения философов, лингвистов, литературоведов. Однако усилия исследователей в этой области были, как правило, сосредоточены на определении ее языкового статуса, разработке классификаций видов и описании лексико-грамматических средств ее создания, а также сравнительном анализе использования гипербол в различных языках. Заметный вклад в изучение гиперболы внесли исследователи, занимающиеся вопросами психолингвистики и когнитивной лингвистики (см.: [Крысин, 2006; Cano Mora, 2006; Claridge, 2011; Colston, O’Brien, 2000; McCarthy, Carter, 2004; Roberts, Kreuz, 1994]). Учеными было установлено, что гипербола обладает двойственной природой, поскольку она не только количественно увеличивает свойства предметов или явлений до предельных размеров, но и, как показано Л. Кано Мора, выражает субъективную оценку объективного факта [Cano Mora, 2006, p. 33]. По мнению Л.П. Крысина, «отсутствие контраста между действительной ситуацией и смыслом описывающего ее высказывания или же отсутствие преувеличивающей оценки говорящим сообщаемых фактов делают невозможным употребление языковых средств для создания именно гиперболического эффекта» [Крысин, 2006, c. 112]. В процессе коммуникации гиперболы используются не только с целью усиления эмоционального тона высказывания, но и для выражения юмора, насмешки, сочувствия, солидарности, антипатии и других эмоций, при этом они также выполняют эвалюативную и персуазивную функции (см. об этом: [McCarthy, Carter, 2004, p. 176]). Очевидно, гиперболы благодаря своей выразительности и оценочности частотны в речи политиков. Однако, несмотря на обилие и разнообразие научных работ, посвященных анализу политического дискурса в целом и характерных для него риторических приемов в частности, гипербола не стала предметом детального изучения, хотя и является, как уже было отмечено, одним из наиболее распространенных тропов в политической риторике. В то же время те немногочисленные современные работы, которые затрагивают тему функционирования гиперболы в политическом дискурсе [Claridge, 2011; Kalkhoven, De Landtsheer, 2016; Mattiello, 2016; Snoeck Henkemans, 2017], свидетельствуют о том, что высказывания гиперболического характера - это мощное орудие убеждения в политических выступлениях, используемое, как отмечает К. Клэридж, для того, чтобы подчеркнуть серьезность ситуации, актуализировать необходимость совершения какого-либо действия, подвергнуть критике позицию или действия политического оппонента и представить в выгодном свете свою партию или политический курс [Claridge, 2011, p. 265]. Таким образом, в речи политиков гипербола может употребляться в качестве средства убеждения, то есть выполнять персуазивную функцию, которая, по мнению Е. Маттиелло, является наиболее значимой для политической риторики с ее ярко выраженной аргументативностью [Mattiello, 2016, p. 160].

Цель данной работы - выявить и описать персуазивность гипербол в британском политическом дискурсе. Материалом для анализа послужили высказывания британских политиков, посвященные теме так называемого инцидента в Солсбери - покушения на бывшего российского разведчика С. Скрипаля и 
его дочь в английском городе Солсбери в марте 2018 года. Выбор материала исследования обусловлен наличием в анализируемых высказываниях риторически выразительных случаев употребления гипербол с целью убеждения. Актуальность работы обусловлена необходимостью более глубокого и детального изучения функций гиперболы в политическом дискурсе, а также расширения представлений о роли этого приема в формировании у реципиента определенного отношения к предмету сообщения.

\section{Методология исследования}

В работе за основу принимается трактовка гиперболы как преувеличенной формы высказывания, в котором слова или словосочетания представляют реальность в крайней степени [Kalkhoven, De Landtsheer, 2016, p. 186]. Данное определение является наиболее приемлемым, поскольку позволяет охватить различные виды преувеличения, используемые говорящим для решения поставленных им риторических и прагматических задач.

В античной риторике, преимущественно в трудах римского ритора Квинтилиана, гиперболе приписываются две эпистемологические функции, актуализирующие, по словам Дж. Риттера, ее разрушительный и трансформативный характер: выражение возможного посредством невозможного и представление лжи как элемента правды [Ritter, 2010, p. 24]. Детальное изучение данных функций позволило Дж. Риттеру вывести метафункцию, или «закон» гиперболы: переориентация посредством дезориентации [Ritter, 2010 , p. 22]. Как подчеркивает ученый, сформулировать содержание метафункции ему помогло высказывание философа П. Рикера о том, что гипербола переориентирует после того как дезориентирует (закон парадокса и гиперболы) и заставляет экстраординарное проявляться в ординарном (закон избыточности) [Ricoeur, 1995, p. 229]. Преувеличение направлено на дезориентацию целевой аудитории, чтобы затем настроить ее на восприятие еще неосознаваемых представлений и реальностей. Соответственно, по Дж. Риттеру, основная цель говорящего, употребляющего в своей речи гиперболы, - изменить представления или эмоциональное состояние адресата сообщения [Ritter, 2010, p. 163]. Способность преувеличения модифицировать мнения, знания, чувства и отношения может использоваться оратором для решения определенных коммуникативных задач, например, для убеждения целевой аудитории в правильности его позиции по какому-либо вопросу. Поскольку гипербола, как отмечает Дж. Риттер, является чрезвычайно рискованным тропом, в ее восприятии важную роль играют этос и пафос [Ritter, 2010, p. 141]. Эффективность гиперболы, как никакого другого тропа, зависит от готовности или предрасположенности целевой аудитории к преувеличению и избыточности, то есть от этоса, и поэтому ее использование является контекстуально-обусловленным. Именно этос и пафос создают субъективное обоснование употребления приема преувеличения в речи [Ritter, 2010, p. 208]. Однако, будучи детерминированной условиями речевой ситуации (этосом) и эмоциональным фоном речевой ситуации (пафосом), гипербола может влиять на реализацию данных риторических категорий в высказывании. Ее способность апеллировать к пафосу, этосу и логосу, выраженный трансформативный характер обусловливают частое использование этого приема с целью убеждения. В работе К. Клэридж показано, что применительно к логосу гипербола может заметно усилить некоторые аспекты доказательств и при этом ослабить другие; применительно к пафосу - представить явления и события как более важные, более пугающие или более желательные и таким образом вызвать у реципиента определенные чувства; что касается этоса, то оратор, склонный к постоянному преувеличению, может произвести впечатление человека, не заслуживающего доверия, в то время как оратор, который постоянно преуменьшает, может показаться неубедительным или скучным - вот почему степень преувеличения должна быть аккуратно выверенной [Claridge, 2011, p. 217].

Анализ высказываний британских политиков на тему инцидента в Солсбери свидетельствует о том, что используемые ими гиперболы апеллируют ко всем трем аспектам убеждения. 


\section{Результаты и обсуждение}

\author{
Гипербольы в речи \\ британского представителя в ООН \\ Карен Пирс
}

В выступлении на заседании Совета безопасности от 5 апреля 2018 г. британский представитель в ООН Карен Пирс называет химическое вещество, которым, согласно докладу британских экспертов, были отравлены С. Скрипаль и его дочь, «оружием массового поражения», а само покушение - «попыткой убить мирных жителей на британской земле»:

(1) We all know that investigation is under ways, it's because a military grade nerve agent was used in an attempt to kill civilians on British soil. It was carried out recklessly, and it was carried out without regard for public safety. It was a weapon of mass destruction(VII).

В данном коммуникативном контексте эти формулировки имеют выраженный гиперболический характер, поскольку семантически они относятся к военной терминологии и традиционно используются для описания действий и событий, происходящих в зоне активных военных действий. Эффект преувеличения создается также при помощи аналогии, которую К. Пирс проводит между масштабными химическими атаками в Сирии в 2014 и 2017 гг. и происшествием в английском провинциальном городке:

(2) Mr. President, there should be no more victims of chemical weapons attacks, whether they take place in the warzone of Syria or in an English country town (V).

Следуя логике высказывания, инцидент в Солсбери является атакой с применением химического оружия и не уступает по своей общественной значимости официально подтвержденным случаям массовых потерь среди гражданского населения во время сирийского военного конфликта. В другом контексте прагматический эффект аналогии усиливается за счет использования стилистического приема аллитерации (in Syria and in Salisbury), позволяющего сделать заявление К. Пирс еще более эмоционально выразительным и запоминающимся:
(3) But we cannot ignore what has happened in Salisbury. We cannot ignore Russia turning a blind eye to the use of chemical weapons in Syria and in Salisbury (VII).

Употребление британским политиком данных гиперболических высказываний имеет целью убедить адресата сообщения в том, что происшедшее событие представляет смертельную угрозу для граждан страны.

В выступлении от 4 апреля 2018 г. К. Пирс квалифицирует инцидент в Солсбери как событие, «подвергающее риску международный порядок». Обращаясь к аудитории с призывом предпринять необходимые меры по защите институтов международного права, К. Пирс использует гиперболические высказывания, актуализирующие масштаб трагических последствий, которые могут иметь место, если собравшиеся не поддержат ее позицию по данному вопросу. В частности, она заявляет, что «если мы не предпримем действий, мы подведем жителей Сирии, мы подведем жителей Солсбери и мы подведем весь мир»:

(4) The rules-based international order and its institutions are too valuable to be put at risk in this way. It is our collective duty to protect them and seek accountability for those who choose to defy them. We fail the people of Syria, we fail the people of Salisbury, we fail the world if we $\operatorname{don} \operatorname{not} \operatorname{act}(\mathrm{V})$.

В данном случае интенсификация гиперболического эффекта достигается за счет использования стилистического приема градации: степень преувеличения, выражаемая следующими друг за другом гиперболами, достигает своего максимального значения в последнем элементе трехчленной цепочки. Особое ритмико-синтаксическое построение предложения, основанное на анафоре, способствует усилению эмоционального, обличительного тона высказывания.

В рассмотренных высказываниях гиперболы апеллируют не только к знаниям адресата, но и его эмоциям (страху, тревоге), а также чувству ответственности. Характеризуя преувеличения в аспекте этоса, отметим, что они настолько искусно встроены в речевой контекст, что могут быть восприняты буквально. В данном случае немалую роль играет и личность говорящего. Авторитет К. Пирс как высокопоставленного дипломата и экспер- 
та по международным делам, а также коммуникативно уместное использование ею определенной политической лексики и некоторых прагматически значимых аналогий способствуют более успешному принятию адресатом ее оценки происшедшего события. Употребляемые К. Пирс гиперболические выражения воссоздают нужный ей образ, формируя у адресата представление о предмете обсуждения, количественно, а в некоторых случаях и качественно не отражающее реального положения дел. В этом отношении справедливо замечание Псевдо-Лонгина о том, что лучшая гипербола - это та, которая скрывает сам факт того, что она является таковой. Это происходит в том случае, когда гипербола произносится под влиянием эмоций в ситуации великого кризиса [Longinus, 1995, p. 283].

Примером обращения гиперболы к логосу может служить высказывание К. Пирс, в котором приводятся конкретные «доказательства» того, что инцидент является чрезвычайным происшествием национального масштаба:

(5) Following the poisoning on 4 March in Salisbury of Sergei and Yulia Skripal, the UK has launched one of the most comprehensive and complex investigations into the use of a chemical weapon ever, it involves more than $\mathbf{2 5 0}$ police detectives. They are supported by a range of specialist experts and partners. They are trawling through more than 5000 hours of CCTV. They are examining more than $\mathbf{1 , 3 5 0}$ seized exhibits. And they are interviewing more than $\mathbf{5 0 0}$ witnesses (VII).

К. Пирс заявляет, что «Соединенное Королевство предприняло одно из самых всесторонних и комплексных из когда-либо проводившихся расследований применения химического оружия, в котором были задействованы более 250 полицейских и большое количество экспертов, занимающихся просмотром более 5000 часов записи с камер видеонаблюдения, изучением более 1350 предметов и допросом более 500 свидетелей». Несмотря на то, что количественные данные, как правило, приводятся с целью конкретизировать ситуацию и составить у адресата более четкое представление о происходящих событиях, в данном случае их использование носит отнюдь не информативный характер. В высказывании К. Пирс они призваны сформировать у адре- сата сообщения представление о чрезвычайной важности обсуждаемой проблемы. Этот прием аргументации, названный Т.А. ван Дейком «игрой в числа» (number game), часто употребляется в политическом дискурсе с целью придать реплике объективность и достоверность. Кроме того, он является риторическим средством создания эмфазы и гиперболизации [Dijk, 2005, p. 87]. Действительно, в рассматриваемом примере не столь принципиально важно, какое именно количество полицейских участвовало в расследовании - 250 или 285 , какое именно количество свидетелей было допрошено - 500 или 520. Эти цифры в первую очередь призваны подчеркнуть общественную значимость инцидента в Солсбери и создать у целевой аудитории представление о существовании угрозы для жизни и благополучия британцев.

\section{Гиперболь в речи}

\section{британского премьер-министра Терезы Мэй}

В своих выступлениях на тему инцидента в Солсбери Тереза Мэй, бывшая тогда премьер-министром Великобритании, употребляет гиперболические высказывания, актуализирующие не только высокую общественную, но и политическую значимость события. В частности, в парламентской речи от 14 марта 2018 г. она характеризует это событие как «использование боевого отравляющего вещества в Европе» и «незаконное применение силы российским государством против Соединенного Королевства» на фоне «сложившейся модели агрессии российского государства в Европе и за ее пределами»:

(6) They have treated the use of a military grade nerve agent in Europe with sarcasm, contempt and defiance. So Mr. Speaker, there is no alternative conclusion other than that the Russian State was culpable for the attempted murder of Mr. Skripal and his daughter - and for threatening the lives of other British citizens in Salisbury, including Detective Sergeant Nick Bailey. This represents an unlawful use of force by the Russian State against the United Kingdom. And as I set out on Monday it has taken place against the backdrop of a well-established pattern of Russian State aggression across Europe and beyond (IV). 
В первом предложении вместо топонима Salisbury (Солсбери) употреблено название части света Europe (Европа), имеющее обобщающее значение и при этом указывающее на место происшествия. Это обусловливает расширение масштаба описываемого события в географическом плане, а использование таких синонимичных единиц, как unlawful use of force (незаконное применение силы) и aggression (агрессия), увеличивает его значимость в политическом плане. Учитывая, что случаи применения боевых отравляющих веществ в Европе были зафиксированы только во время Первой и Второй мировых войн, а агрессия определяется Уставом ООН как применение вооруженной силы государством против суверенитета, территориальной неприкосновенности или политической независимости другого государства (IX), можно утверждать, что указанные слова и словосочетания являются гиперболами. В этом же выступлении Т. Мэй называет происшедшее событие «угрозой национальной безопасности»:

(7) So this debate is taking place, Mr. Speaker, because there is no greater responsibility for this House - for this government and for me as Prime Minister - than recognizing threats to our national security and acting to meet them (IV).

Оценка, которую в своем высказывании британский премьер-министр дает инциденту в Солсбери, является существенно преувеличенной и не соответствует действительности. Согласно информации, представленной на официальном сайте правительства Великобритании, к основным угрозам национальной безопасности относятся терроризм, шпионаж, кибератаки и распространение оружия массового поражения, которые могут оказать воздействие на национальную инфраструктуру Соединенного Королевства (I), что не позволяет расценивать покушение на жизнь двух человек (один из них - британский подданный, другой - гражданин России) как угрозу подобного масштаба и значения. В этом отношении справедливо замечание К. Клэридж о том, что контекст играет важную роль в интерпретации гиперболических высказываний, поскольку то, что является преувеличением в одном случае, может таковым и не быть в другом [Claridge, 2011, p. 12]. Рассмотренные при- меры подтверждают наблюдение Л.П. Крысина, согласно которому «гипербола может создаваться в контексте высказывания - путем смыслового сдвига слов и выражений: от значения единичности к значению регулярности или постоянности действия, от конкретности к обобщенности и т. д.» [Крысин, 2006, с. 118]. В парламентской речи от 26 марта 2018 г., озаглавленной как «PM Commons Statement on National Security and Russia» («Заявления по вопросу национальной безопасности и России»), британский премьер-министр квалифицирует происшедшее событие как «посягательство на наши фундаментальные ценности и международную систему правопорядка», «элемент модели агрессивного поведения России», а также как «новую и опасную фазу во враждебной деятельности России на нашем континенте и за его пределами»:

(8) It was an assault on our fundamental values and the rules based international system that upholds them. And it was part of a pattern of increasingly aggressive Russian behavior, but which - with the first offensive use of a nerve agent on European soil since the foundation of NATO - also represents a new and dangerous phase in Russia's hostile activity within our continent and beyond (III).

Примечательно, что в словосочетаниях our fundamental values (наши фундаментальные ценности) и within our continent (на нашем континенте) референтами притяжательного местоимения our (наш) являются Т. Мэй и европейцы, а не британцы. Следовательно, дейктическая единица our участвует в конструировании дискурса «общего дела», актуализирующего солидарность позиции британского премьер-министра и европейских политиков по обсуждаемой теме.

В аспекте апелляции к логосу рассмотренные гиперболы актуализируют представления о том, что происшедшее событие является опасностью для жизни и благополучия европейцев. При этом оказывается эмоциональное воздействие на адресата: данные высказывания создают определенный патетический настрой, позволяющий говорящему убедить слушающего в правильности и целесообразности предлагаемых им действий. На выраженную эмоциональность использования гипербол указывают многие исследователи. 
Так, Г. Колстон и Дж. О’Браен отмечают, что гиперболы подчеркивают несоответствие между ожиданиями или желаниями говорящего и реальным положением дел. Поэтому многие люди используют их для выражения своего недовольства происходящим [Colston, 2015, p. 95]. К. Клэридж указывает, что при помощи преувеличения говорящие передают свое эмоциональное отношение к событиям и ситуациям, при этом степень контраста между гиперболическим высказыванием и реальным положением дел зависит от силы выражаемого чувства [Claridge, 2011, p. 20]. В рассмотренных выше примерах высокая степень контраста между гиперболами и событием, которое они характеризуют, свидетельствует о крайнем недовольстве и возмущении британского премьер-министра. Использование преувеличений в речи преследует цель вызвать такие же эмоции и у аудитории. В аспекте этоса данные гиперболические выражения, преимущественно представляющие собой термины политологии и международного права, позволяют Т. Мэй подчеркнуть свой статус политика высокого мирового уровня, владеющего необходимыми знаниями, а также позиционировать себя как сильного и ответственного лидера, заботящегося о безопасности и благополучии своих граждан.

\section{Гиперболы в речи \\ британского министра иностранных дел Бориса Джсонона}

Свое мнение по поводу инцидента в Солсбери Борис Джонсон, министр иностранных дел с 2016 по 2018 г., представил вниманию общественности не в официальных пресс-релизах подведомственного ему министерства, а в информационно-аналитических статьях, опубликованных в британской прессе. Эти статьи написаны в соответствии с функционально-стилистическими особенностями языка средств массовой информации и характеризуются использованием риторических средств, создающих экспрессивность и образность. В частности, одним из таких средств являются метафорические гиперболы. Согласно исследованиям языка СМИ, медиатексты «изобилуют тропами, сравнениями, метафорами и прочими стилистическими приемами, которые используются для оказания воздействия на аудиторию. При этом особое внимание уделяется функционированию метафор, способность которых емко отображать действительность с помощью ярких запоминающихся образов активно используется в журналистской практике всего мира» [Добросклонская, 2008, с. 52]. Известно, что гипербола, как никакой другой троп, обладает способностью сочетаться с разными фигурами речи: метафорой, иронией, метонимией, эпитетом, антитезой и др. (подробно об этом см., например, [Carston, Wearing, 2015, p. 82]). Coвместное употребление метафоры и гиперболы может способствовать усилению выразительности и убедительности высказывания.

В статьях Б. Джонсона метафорические гиперболы используются для характеристики официальной позиции и заявлений российского правительства по делу о покушении на С. Скрипаля и его дочь. В статье, опубликованной в газете «Телеграф» 20 марта 2018 г., политик заявляет, что «Россия прибегает к своей обычной стратегии, заключающейся в том, чтобы спрятать иголку правды в стоге лжи и путаницы»:

(9) The Russian state is resorting to its usual strategy of trying to conceal the needle of truth in a haystack of lies and obfuscation (VI).

В своем высказывании он перефразирует идиоматическое выражение look for a needle in a haystack (искать иголку в стоге сена), которое представляет собой так называемый адинатон - разновидность гиперболы, выражающей преувеличение в настолько высокой степени, что описываемая при ее помощи гипотетическая ситуация в принципе не может быть возможной (ЕВ). Использование хорошо известной поговорки и экспрессивной метафорической гиперболы a haystack of lies and obfuscation позволяет сделать высказывание более выразительным и запоминающимся. Прагматически значимым является актуализируемое указанной идиомой противопоставление «истинное положение дел - ложные заявления», поскольку в данном контексте оно обусловливает вывод инференции о том, что именно Россия несет ответственность за случившееся: если заявления российского правительства о непричастности к ин- 
циденту в Солсбери ложны, то правда заключается в том, что оно на самом деле к нему причастно. В статье, вышедшей в газете «Таймс» 27 марта 2018 г., британский политик употребляет метафорическую гиперболу a deluge of lies (поток лжи) для характеристики заявлений российского правительства, опубликованных в СМИ:

(10) Our allies have not been deterred by Russia's usual tactics for avoiding pressure. Sure enough, the Kremlin began pumping out a deluge of lies almost as soon as Sergei and Yulia Skripal had entered intensive care (VIII).

В другом материале, представленном вниманию читателей в газете «Сандэй Таймс» 8 апреля 2018 г., Б. Джонсон использует две гиперболы в словосочетаниях an avalanche of lies and disinformation (лавина лжи и дезинформации) и the torrent of absurdity (поток абсурда):

(11) The essence of a Kremlin cover-up is a cynical attempt to bury awkward facts beneath an avalanche of lies and disinformation....This time, the torrent of absurdity has availed the Kremlin little: 28 countries and NATO delivered their emphatic answer by siding with Britain and evicting more than 150 Russian diplomats, the largest collective expulsion in history (II).

В приведенных примерах Б. Джонсон называет заявления российского правительства по поводу инцидента в Солсбери ложью, абсурдом, дезинформацией, а также использует гиперболы, актуализирующие неправдоподобный, угрожающе большой объем этих заявлений, что в данном контексте способствует усилению негативного впечатления. Кроме того, указанные гиперболы создают особый эффект обобщения, благодаря которому любые заявления российских властей расцениваются как ложные. В дискурсе данный эффект обобщения реализуется и другими языковыми средствами: прилагательным usual (обычный): The Russian state is resorting to its usual strategy, вводной конструкцией sure enough (конечно же), а также обстоятельством времени this time, употребленными с целью формирования у аудитории представления о том, что действия России, о которых идет речь, совершались ранее и вполне ожидаемы.
В аспекте пафоса указанные негативнооценочные метафорические гиперболы, апеллирующие к разрушительным и смертельно опасным явлениям природы, обусловливают формирование отрицательного отношения к предмету высказывания. С точки зрения этоса употребление таких образных, даже художественных выражений в официальной речи политического деятеля было бы неуместно, а в текстах публицистического стиля, напротив, вполне приемлемо и оправданно.

\section{Заключение}

Проведенный анализ показал, что использование гипербол в политическом дискурсе имеет выраженную персуазивную направленность. Они обусловливают реализацию функции убеждения посредством обращения к логосу, пафосу и этосу. Применительно к логосу гиперболы актуализируют высокую общественную и политическую значимость характеризуемого при их помощи события. Применительно к пафосу гиперболы выражают негативное эмоциональное отношение говорящего к предмету сообщения (негодование, возмущение) и имеют целью вызвать аналогичные эмоции у аудитории, что обусловливает их частое использование в политическом дискурсе для критики и дискредитации оппонента и его действий. Эффективность гиперболы как инструмента убеждения в политике в значительной степени зависит от этоса, то есть условий речевой ситуации, детерминирующих уместность употребления данного риторического приема, и личности говорящего. Использование политиком гипербол, семантически и ситуационно соотносимых с его профессиональной компетенцией и сферой деятельности (например, дипломатия, международная политика), способствует более успешному принятию данных преувеличивающих выражений, содержание которых воспринимается адресатом как правильное и/или соответствующее действительности. В некоторых высказываниях гиперболы настолько искусно встроены в коммуникативный контекст, что могут восприниматься буквально. Употребление образных метафорических гипербол с целью формирования у адресата определенного отношения к предмету сообщения зафиксиро- 
вано только в публицистических текстах информационно-аналитического типа и обусловлено функционально-стилистическими особенностями языка СМИ. В политическом дискурсе взаимодействие преувеличения с другими риторическими приемами (аналогией, аллитерацией, анафорой, градацией) делает высказывание более экспрессивным и убедительным. В некоторых случаях негативно-оценочные метафорические гиперболы совместно с лексическими средствами могут создавать контекстуальный эффект обобщения, позволяющий придать большую убедительность заявлениям адресанта. Важную роль в реализации персуазивной функции гиперболы в политическом дискурсе играет ее эвокативность, то есть способность вызывать определенные представления, в рамках которых объект гиперболической репрезентации приобретает свойства, значительно отличающиеся от его реальных характеристик в количественном, а иногда и качественном отношении.

\section{СПИСОК ЛИТЕРАТУРЫ}

Добросклонская Т. Г., 2008. Медиалингвистика: системный подход к изучению языка СМИ: современная английская медиаречь. М. : Флинта : Наука. 264 с.

Крысин Л. П., 2006. Гипербола в художественном тексте и в обыденной речи // Язык художественной литературы. Литературный язык : сб. ст. к 80-летию М.Б. Борисовой. Саратов : Научная книга. С. 112-120.

Cano Mora L., 2006. How to Make a Mountain Out of a Molehill. A Corpus-Based Pragmatic and Conversational Analysis Study of Hyperbole in Interaction. Valencia : University of Valencia Press. 328 p.

Carston R., Wearing C., 2015. Hyperbolic Language and its Relation to Metaphor and Irony // Journal of Pragmatics. Vol. 79. P. 79-92.

Claridge C., 2011. Hyperbole in English. A CorpusBased Study of Exaggeration. Cambridge : Cambridge University Press. 325 p.

Colston H. L., 2015. Using figurative language. Cambridge : Cambridge University Press. 284 p.

Colston H., O'Brien J., 2000. Contrast of Kind Versus Contrast of Magnitude: The Pragmatic Accomplishments of Irony and Hyperbole // Discourse Processes. Vol. 30, iss. 2. P. 179-199.

Dijk T. A. van, 2005. War Rhetoric of a Little Ally // Journal of Language and Politics. Vol. 4. P. 65-91.
Kalkhoven L., De Landtsheer Ch., 2016. Politics, It Has Never Been So Simple. Complex Versus Simple Rhetoric and the Use of Hyperbole in Political Decision-making in the Netherlands // Complex political decision-making. Leadership, Legitimacy and Communication / P. Bursens (ed.). London : Taylor and Francis. P. 183-198.

Longinus, 1995. On the Sublime. The Loeb Classical Library / transl. by W. H. Fyfe. Cambridge : Harvard University Press. 533 p.

Mattiello E., 2016. Understatement and Overstatement: Two Powerful Persuasive Tools in English and Italian Political Speeches // The language of politics $=$ La politique et ses langages $/$ M. Degani, P. Frassi, M. Ivana Lorenzetti (eds.). Cambridge : Cambridge Scholars Publishing. Vol. 1. P. 159-178.

McCarthy M., Carter R., 2004. There's Millions of Them: Hyperbole in Everyday Conversation // Journal of Pragmatics. Vol. 36, iss. 2. P. 149-184.

Ricoeur P., 1995. Figuring the Sacred: Religion, Narrative, and Imagination / transl. by D. Pellauer. Minneapolis : Fortress Press. 340 p.

Ritter J., 2010. Recovering Hyperbole: Re-Imagining the Limits of Rhetoric for an Age of Excess. Dissertation. Atlanta : Georgia State University. $326 \mathrm{p}$.

Roberts R., Kreuz R., 1994. Why do people use figurative language? // Psychological Science. Vol. 5. P. 159-163.

Snoeck Henkemans A. F., 2017. Strategic Maneuvering with Hyperbole in Political Debate//Contextualizing Pragma-Dialectics / F. H. van Eemeren, W. Peng (eds.). Amsterdam : John Benjamin Publishing Company. P. 269-280.

\section{ИСТОЧНИКИ}

I- National Security Threats // Centre for the Protection of National Infrastructure. URL: https:// www.cpni.gov.uk/national-security-threats.

II - Only Russia could have committed this crime: article by Boris Johnson // Gov.uk. URL: https://www.gov.uk/government/speeches/ only-russia-could-have-committed-thiscrime-article-by-boris-johnson.

III - PM Commons statement on National Security and Russia: 26 March 2018 // Gov.uk. URL: https://www.gov.uk/government/speeches/pmcommons-statement-on-national-security-andrussia-26-march-2018.

$I V$ - PM Commons Statement on Salisbury incident response: 14 March 2018// Gov.uk. URL: https:// www.gov.uk/government/speeches/pmcommons-statement-on-salisbury-incidentresponse-14-march-2018. 
$V$ - Protecting Victims of Chemical Weapons Attacks in Syria, Salisbury and Internationally // Gov.uk. URL: https://www.gov.uk/government/speeches/ protecting-victims-of-chemical-weapons-attacksin-syria-salisbury-and-internationally.

$V I$ - Putin's sinister threats and lies extend far beyond his own country: article by Boris Johnson // Gov.uk. URL: https://www.gov.uk/ government/speeches/putins-sinister-threatsand-lies-extend-far-beyond-his-own-countryarticle-by-boris-johnson.

$V I I$ - We cannot ignore what has happened in Salisbury: UN Security Council statement, 5 April 2018 // Gov.uk. URL: https://www.gov.uk/ government/speeches/we-cannot-ignore-whathas-happened-in-salisbury.

VIII-West takes a stand to halt reckless ambitions: article by Boris Johnson // Gov.uk. URL: https://www. gov.uk/government/speeches/west-takes-a-standto-halt-reckless-ambitions-article-by-borisjohnson.

$I X$ - Определение агрессии // Конвенции и соглашения. URL: https://www.un.org/ru/documents/ decl_conv/conventions/aggression.shtml.

$E B$ - Encyclopedia Britannica. URL: https://www. britannica.com/art/adynaton.

\section{REFERENCES}

Dobrosklonskaya T.G., 2008. Medialingvistika: sistemnyy podkhod k izucheniyu yazyka SMI: sovremennaya angliyskaya mediarech [Medialinguistics: A System Approach to Studying the Language of Mass Media: Contemporary English Media Speech]. Moscow, Flinta Publ., Nauka Publ. 264 p.

Krysin L.P., 2006. Giperbola v khudozhestvennom tekste i v obydennoy rechi [Hyperbole in Fiction and in Everyday Speech]. Yazik khudozhestvennoy literatury. Literaturnyy yazik: sb. k 80-letiyu M.B. Borisovoy [Language of Fiction. Literary Language. Collection of Articles to the $80^{\text {th }}$ Anniversary of M.B. Borisova]. Saratov, Nauchnaya kniga Publ., pp. 112-120.

Cano Mora L., 2006. How to Make a Mountain out of a Molehill. A Corpus-Based Pragmatic and Conversational Analysis Study of Hyperbole in Interaction. Valencia, University of Valencia Press. 328 p.

Carston R., Wearing C., 2015. Hyperbolic Language and Its Relation to Metaphor and Irony. Journal of Pragmatics, vol. 79, pp. 79-92.

Claridge C., 2011. Hyperbole in English. A CorpusBased Study of Exaggeration. Cambridge, Cambridge University Press. 325 p.
Colston H.L., 2015. Using Figurative Language. Cambridge University Press. 284 p.

Colston H., O'Brien J., 2000. Contrast of Kind Versus Contrast of Magnitude: The Pragmatic Accomplishments of Irony and Hyperbole. Discourse Processes, vol. 30, iss. 2, pp. 179-199.

Dijk T.A. van, 2005. War Rhetoric of a Little Ally. Journal of Language and Politics, vol. 4, pp. 65-91.

Kalkhoven L., De Landtsheer Ch., 2016. Politics, It Has Never Been So Simple. Complex Versus Simple Rhetoric and the Use of Hyperbole in Political Decision-making in the Netherlands. Bursens P., ed. Complex Political DecisionMaking. Leadership, Legitimacy and Communication. London, Taylor and Francis, pp. 183-198.

Longinus, 1995. On the Sublime. The Loeb Classical Library. Cambridge, Harvard University Press. $533 \mathrm{p}$.

Mattiello E., 2016. Understatement and Overstatement: Two Powerful Persuasive Tools in English and Italian Political Speeches. Degani M., Frassi P., Ivana Lorenzetti M., eds. The Language of Politics $=$ La politique et ses langages. Cambridge, Cambridge Scholars Publishing, vol. 1, pp. 159-178.

McCarthy M., Carter R., 2004. There's Millions of Them: Hyperbole in Everyday Conversation. Journal of Pragmatics, vol. 36, iss. 2, pp. 149-184.

Ricoeur P., 1995. Figuring the Sacred: Religion, Narrative, and Imagination. Minneapolis, Fortress Press. 340 p.

Ritter J. Recovering Hyperbole: Re-Imagining the Limits of Rhetoric for an Age of Excess. Dissertation. Atlanta, Georgia State University. 326 p.

Roberts R., Kreuz R., 1994. Why Do People Use Figurative Language? Psychological Science, vol. 5, pp.159-163.

Snoeck Henkemans A.F., 2017. Strategic Maneuvering with Hyperbole in Political Debate. Eemeren F.H. van, Peng W., eds. Contextualizing Pragma-Dialectics. Amsterdam, John Benjamin Publishing Company, pp. 269-280.

\section{SOURCES}

National Security Threats. Centre for the Protection of National Infrastructure. URL: https:// www.cpni.gov.uk/national-security-threats.

Only Russia could have committed this crime: article by Boris Johnson. Gov.uk. URL: https:/// www.gov.uk/government/speeches/onlyrussia-could-have-committed-this-crime-articleby-boris-johnson. 
PM Commons Statement on National Security and Russia: 26 March 2018. Gov.uk. URL: https:// www.gov.uk/government/speeches/pmcommons-statement-on-national-security-andrussia-26-march-2018.

PM Commons Statement on Salisbury Incident Response: 14 March 2018. Gov.uk. URL: https:/www.gov.uk/ government/speeches/pm-commons-statementon-salisbury-incident-response-14-march-2018.

Protecting Victims of Chemical Weapons Attacks in Syria, Salisbury and Internationally. Gov.uk. URL: https://www.gov.uk/government/speeches/ protecting-victims-of-chemical-weapons-attacksin-syria-salisbury-and-internationally.

Putin's Sinister Threats and Lies Extend far Beyond His Own Country: Article by Boris Johnson. Gov.uk. URL: https:/www.gov.uk/government/ speeches/putins-sinister-threats-and-lies- extend-far-beyond-his-own-country-article-byboris-johnson.

We Cannot Ignore What Has Happened in Salisbury: UN Security Council Statement, 5 April 2018. Gov.uk. URL: https://www.gov.uk/government/speeches/ we-cannot-ignore-what-has-happened-in-salisbury.

West Takes a Stand to Halt Reckless Ambitions: Article by Boris Johnson. Gov.uk. URL: https:// www.gov.uk/government/speeches/west-takesa-stand-to-halt-reckless-ambitions-article-byboris-johnson.

Opredelenie agressii [Definition of Aggression]. Konventsii i soglasheniya [Conventions and Agreements]. URL: https://www.un.org/ ru/documents/decl_conv/conventions/ aggression.shtml.

Encyclopedia Britannica. URL: https://www. britannica. com/art/adynaton.

\section{Information about the Author}

Tatyana M. Golubeva, Candidate of Sciences (Philology), Associate Professor, Department of Professional Communication in Foreign Languages, Minin State Pedagogical University of Nizhny Novgorod (Minin University), Ulyanova St., 1, 603950 Nizhny Novgorod, Russia, gtm77@mail.ru, https://orcid.org/0000-0002-3909-5364

\section{Информация об авторе}

Татьяна Михайловна Голубева, кандидат филологических наук, доцент кафедры иноязычной профессиональной коммуникации, Нижегородский государственный педагогический университет им. К. Минина (Мининский университет), ул. Ульянова, 1, 603950 г. Нижний Новгород, Россия, gtm77@mail.ru, https://orcid.org/0000-0002-3909-5364 